\section{Prognostic Value of the Tumor Marker Index Based on Preop- erative Serum Carcinoembryon- ic Antigen and Cytokeratin-19 Fragment Levels for Overall and Disease-Free Survival in Patients with Stage I Non-Small Cell Lung Cancer}

Gaku Yamaguchi ${ }^{1,2 *}$, Masaru Haghiwara ${ }^{3}$ and Norihiko Ikeda $^{3}$

${ }^{1}$ Division of Thoracic Surgery, The International University of Welfare and Health Care Ichikawa Hospital, Chiba, Japan

${ }^{2}$ Department of Thoracic Surgery, Chemotherapy Research Institute, Kaken Hospital, Kohnodai, Ichikawa-shi, Chiba, Japan

${ }^{3}$ Division of Thoracic and Thyroid Surgery, Tokyo Medical University Hospital, Tokyo, Japan

\begin{abstract}
Purpose: Increased preoperative serum Carcinoembryonic Antigen (CEA) and Cytokeratin-19 Fragment (CYFRA 21-1) levels are associated with a poor postoperative prognosis in early-stage Non-Small Cell Lung Cancer (NSCLC). The Tumor Marker Index (TMI), calculated as the mean of the CEA and CYFRA 21-1 levels normalized to their respective diagnostic cutoff values, is a predictor of prognosis. This study aimed to validate the prognostic value of the TMI for Overall Survival (OS) and Disease-Free Survival (DFS) in a large patient population.

Methods: Five-year OS and DFS based on preoperative serum CEA and CYFRA 21-1 levels and the TMI were evaluated in 454 patients (252 men and 202 women) with Stage I NSCLC (median age, 67 [range: $35-86$ ] years) who underwent complete surgical resection. Univariate and multivariate analyses of serum CEA and CYFRA 21-1 levels, and the TMI were performed.
\end{abstract}

*Corresponding author: Gaku Yamaguchi, Department of Thoracic Surgery, Chemotherapy Research Institute, Kaken Hospital, Kohnodai, Ichikawa-shi, Chiba, Japan, Tel: 047-375-1111; Fax: 047-373-4921Email: ugaku@hotmail.com

Citation: Yamaguchi G, Haghiwara M, Ikeda N (2019) Prognostic Value of the Tumor Marker Index Based on Preoperative Serum Carcinoembryonic Antigen and Cytokeratin-19 Fragment Levels for Overall and Disease-Free Survival in Patients with Stage I Non-Small Cell Lung Cancer. J Pulm Med Respir Res 5: 027.

Received: July 22, 2019; Accepted: July 29, 2019; Published: August 05, 2019

Copyright: () 2019 Yamaguchi G, et al. This is an open-access article distributed under the terms of the Creative Commons Attribution License, which permits unrestricted use, distribution, and reproduction in any medium, provided the original author and source are credited.
Results: The 5-year OS and DFS rates were significantly lower for patients with elevated serum CEA/CYFRA 21-1 levels than for patients with normal CEA/CYFRA 21-1 levels. The TMI was also markedly different, demonstrating significantly lower OS and DFS in patients with a TMI of $>0.5(P<0.001)$. Eighty-four patients with normal CEA and CYFRA 21-1 levels had an elevated TMI, which correlated with significantly lower OS and DFS. Multivariate analysis indicated the independent prognostic value of the TMI.

Conclusion: The TMI is an independent preoperative prognostic factor in Stage I NSCLC and should be considered in the decision making for postoperative therapy.

Keywords: Non-Small Cell Lung Cancer; Prognostic Factor; Serum Marker; Survival; Tumor Marker Index

\section{Introduction}

Approximately $80 \%$ of lung cancers are Non-Small Cell Lung Cancer (NSCLC). Improved screening using thoracic computed tomography increased early diagnosis of Stage I NSCLC, as well as, the 5 -year survival after curative surgery [1-4]. Despite optimal surgical treatment, cancer recurs in $>20.0 \%$ of patients. The median post-recurrence survival time ranges from 8.1 to 17.7 months [5]. Tumor size, tumor location and morphology, and lymph node involvement, contribute to disease recurrence. The histological heterogeneity of NSCLC with different clinical presentations makes prognosis difficult [6]. Identification of preoperative serum markers enables more accurate prognosis [7]. Carcinoembryonic Antigen (CEA) and Cytokeratin Fragment 19 (CYFRA 21-1) are two predictive markers that have been extensively studied in lung cancer [8].

Oncofetal glycoprotein CEA is overexpressed in approximately $35-60 \%$ of patients with NSCLC [9]. A number of studies demonstrates that elevated preoperative serum CEA concentrations predict a poor prognosis in early-stage NSCLC [10-13], while others report no prognostic value for Overall Survival (OS) [14-18], but rather associated with tumor histology, smoking $[14,15]$, or postoperative disease recurrence [16-18].

Cytokeratin 19 is expressed in the epithelial lining of the bronchial tree and is overexpressed in lung tumors [19]. The C-terminal fragment of cytokeratin 19 is detected by two specific monoclonal antibodies (Bm 19.21 and Ks 19.1). Elevated serum CYFRA 21-1 was found in lung cancer patients [20,21]. Serum CYFRA 21-1 levels are independent of sex and smoking history[22]. Several reports have demonstrated the independent prognostic value of CYFRA 21-1 for survival and tumor relapse after resection [23-26].

Studies that evaluated the prognostic significance of CEA and CYFRA 21-1in the same patient population with stage I-II NSCLC suggested that only CYFRA 21-1, and not CEA, was an independent prognostic indicator for survival [27] and metastasis [28], while others $[29,30]$, showed that both markers have independent prognostic value. It was also noted that prognosis was dependent on tumor histology: patients with adenocarcinoma, but not squamous cell carcinoma had elevated preoperative CEA associated with shorter survival and 
Citation: Yamaguchi G, Haghiwara M, Ikeda N (2019) Prognostic Value of the Tumor Marker Index Based on Preoperative Serum Carcinoembryonic Antigen and Cytokeratin-19 Fragment Levels for Overall and Disease-Free Survival in Patients with Stage I Non-Small Cell Lung Cancer. J Pulm Med Respir Res 5: 027.

early recurrence.. In contrast, poor prognosis in squamous cell carcinoma was associated with elevated CYFRA 21-1 [31]. Higher serum CEA concentrations in adenocarcinoma patients made it difficult to estimate the CEA cutoff value $[32,33]$.

The combination of tumor markers significantly improves their prognostic ability. Cedrés et al. showed that patients with Stage III-IV NSCLC with elevated three markers, CEA, CYFRA 21-1, and cancer antigen-125, had the poorest prognosis [33]. A similar result was obtained using a combination of CEA, CYFRA 21-1, and neuron-specific enolase [34]. A combination of CYFRA 21-1 and a laminin chain gamma 2 , predicted a poor OS better than any other markers associated with NSCLC [35]. The CEA and CYFRA 21-1 combination is also reported to have higher sensitivity and specificity for the clinical diagnosis of NSCLC [36-38]. CEA and CYFRA 21-1 gene expression signature was also predictive of a favorable outcome [39].

Muley et al. have shown that a geometric mean of the preoperative CEA and CYFRA 21-1 levels normalized to their respective diagnostic cutoff values, called tumor marker index (TMI), has a prognostic significance [40]. The same authors [41] and subsequently Tomita et al. [42] later confirmed these findings, while Blankenburg et al. [43] found no association between elevated preoperative TMI and a poor postoperative prognosis.

To resolve this controversy, this study investigates the usefulness of the TMI in a large patient population with equal number of men and women. We demonstrate that TMI is an independent prognostic factor for postoperative 5-year OS and disease-free survival (DFS) in patients with Stage I NSCLC.

\section{Materials and Methods}

Subjects: All study participants have provided informed written consent. The study was approved by the Ethics Committee Ethics Committee of Tokyo Medical University (Tokyo, Japan). The research was conducted in accordance with the Declaration of Helsinki.

This retrospective study included 454 patients with Stage I NSCLC who underwent complete surgical resection, consisting of a lobectomy and lobe-specific selective lymph node dissection, at Tokyo Medical University Hospital between January 2006 and December 2009. Lymph node dissection was performed in all cases. The cohort comprised 252 men and 202 women, with a median age of 67 (range: 35-86) years. Patients were followed up for $\geq 5$ years or until death. The overall postoperative follow-up period ranged from 46 to 2,955 days (1.5-97.2 months), with a mean of 2,004 days or 65.9 months.

Tumor size and histology: Histological evaluations were performed at our hospital's Department of Surgical Pathology. Two independent pathologists specializing in lungs and other mediastinal organs performed the histological evaluations. Among the 454 patients, 378 had adenocarcinoma, 61 had squamous cell carcinoma, and 15 had other lung cancers (large cell carcinoma $[\mathrm{n}=10]$, adenocarcinoma with large cell carcinoma $[\mathrm{n}=3]$, and pleomorphic carcinoma $[\mathrm{n}=2])$. Patients who underwent preoperative treatment, as well as, those with incomplete or partial resection (e.g., segmentectomy) and patients with lowgrade malignant tumors (e.g., carcinoid or mucoepidermoid carcinomas) were excluded from the study (Figure 1A).

Carcinoembryonic antigen and cytokeratin-19 fragment measurements: Preoperative serum CEA and CYFRA 21-1 levels were measured in the in-house hospital clinical laboratory in 448 and 348 patients, respectively. The normal upper limits for serum CEA and CYFRA 21-1 levels were 5.0 and $3.3 \mathrm{ng} / \mathrm{mL}$, respectively. The TMI was calculated as the geometric mean of the CEA and CYFRA 21-1 levels normalized to their respective diagnostic cutoff values (5.0 and $3.3 \mathrm{ng} / \mathrm{mL}$, respectively) in 346 patients in whom both markers had been measured, using the following equation [40].

$$
T M I=\sqrt{\left(\frac{\text { serumCEAlevel }}{5.0}\right) \times\left(\frac{\text { serumCYFRA21.1level })}{3.3}\right)}
$$

Statistical analyses: Receiver operating characteristic (ROC) curve analysis was performed to identify the optimal TMI cutoff value for predicting probable OS and DFS rates. The point with the greatest combined specificity and sensitivity was chosen according to the area under the ROC curve analysis ( 0.675 [95.0\% confidence interval]: 0.591-0.760). The optimal TMI cutoff value for predicting postoperative survival was 0.5 according to min (1-sensitivity) $2+$ (1-specificity) 2 expression that takes both sensitivity and specificity into account (Figure 1B).

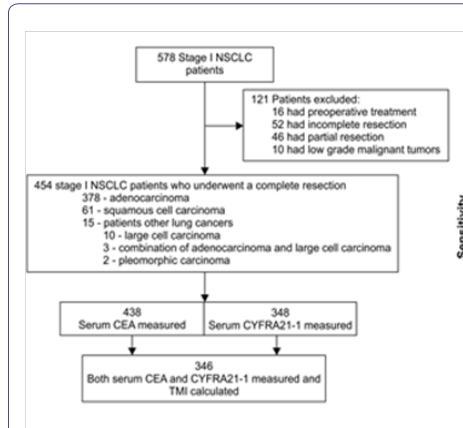

Figure 1A

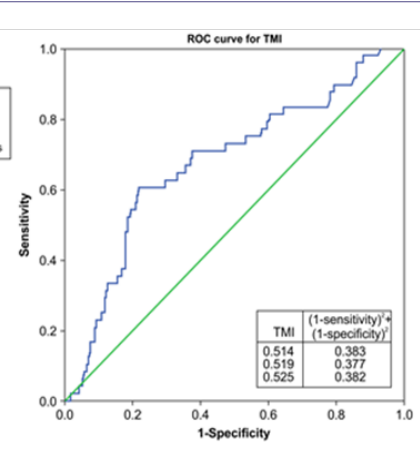

Figure 1B
Figure 1: (A) Flow chart of patient recruitment and (B) Receiver Operating Characteristic (ROC) curve for determining the Tumor Marker Index (TMI) cutoff value. Abbreviations: $\mathrm{CEA}=$ carcinoembryonic antigen; CYFRA 21-1=cytokeratin-19 fragment; NSCLC $=$ non-small cell lung cancer.

Postoperative OS and DFS curves were plotted according to the Kaplan-Meier method. OS was measured from the date of surgery to the date of death or last follow-up. A log-rank test was performed to evaluate the significance of differences in survival rates among the groups. A $\mathrm{P}<0.05$ was considered statistically significant. Multivariate analysis using the Cox proportional hazards model was used to establish the association between tumor size and CEA and CYFRA 21-1 levels and the TMI. Additional characteristics (age, sex, smoking history, and tumor histology) were included in the univariate analysis. All statistical analyses were conducted using Statistical Package for the Social Sciences for Windows (software version 24.0; IBM Corp., Armonk, NY, USA).

\section{Results}

Patient description and marker levels:The cohort consisted of 454 patients. The median age prior to surgery was 67 (range: $35-86$ ) years, with $77.8 \%$ of patients $<75$ years. All of the patients had Stage I disease. The patient characteristics are summarized in Table 1. 
Citation: Yamaguchi G, Haghiwara M, Ikeda N (2019) Prognostic Value of the Tumor Marker Index Based on Preoperative Serum Carcinoembryonic Antigen and Cytokeratin-19 Fragment Levels for Overall and Disease-Free Survival in Patients with Stage I Non-Small Cell Lung Cancer. J Pulm Med Respir Res 5: 027.

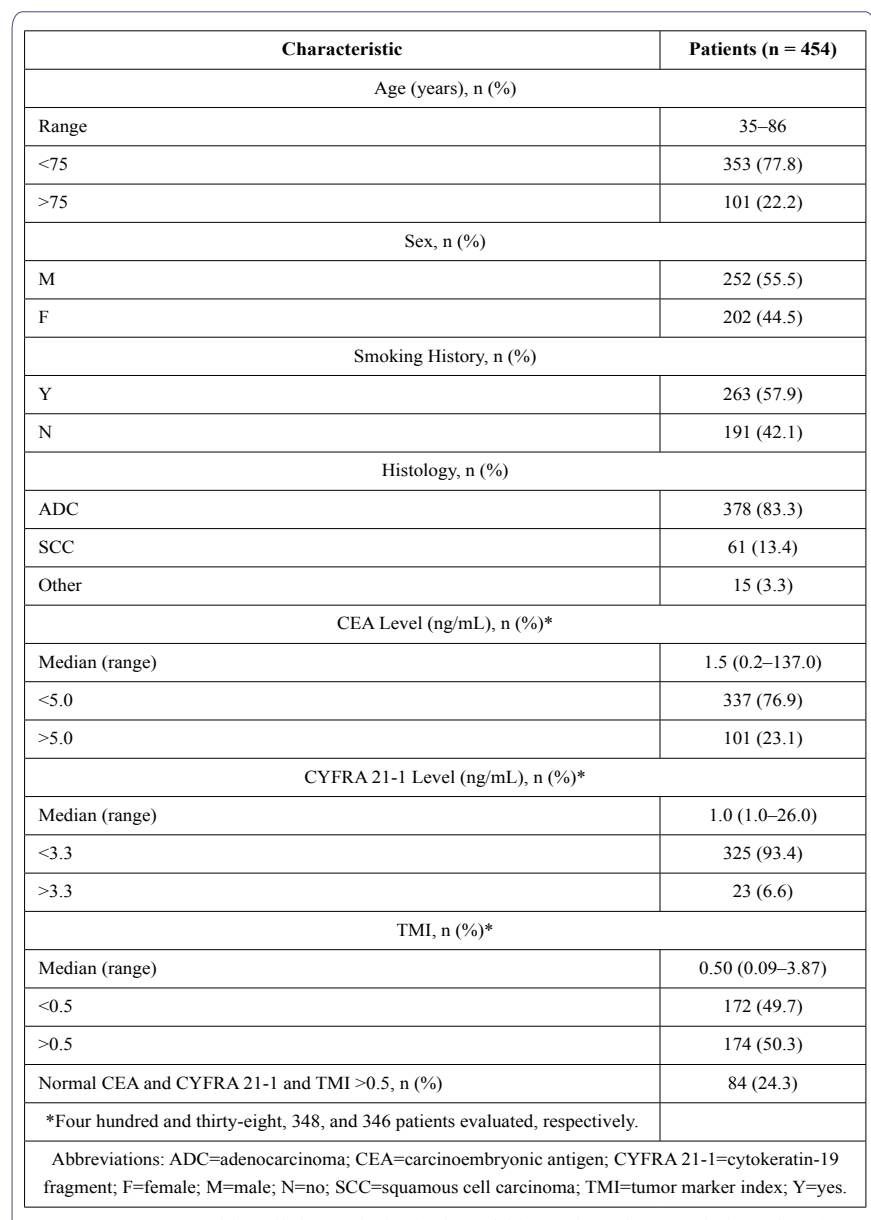

Table 1: Demographic, clinicopathological, and biomarker characteristics of patients with stage I non-small cell lung cancer.

Preoperative serum CEA levels ranged from 0.2 to $137.0 \mathrm{ng} / \mathrm{mL}$ (median: $1.5 \mathrm{ng} / \mathrm{mL}$ ); $23.1 \%$ of patients had elevated CEA levels of $>5.0 \mathrm{ng} / \mathrm{mL}$. CYFRA $21-1$ levels ranged from 0.1 to $212.0 \mathrm{ng} / \mathrm{mL}$ (median: $1.0 \mathrm{ng} / \mathrm{mL}$ ); $6.6 \%$ of patients had elevated CYFRA $21-1$ levels of $>3.3 \mathrm{ng} / \mathrm{mL}$. In 346 patients, both markers had been measured, and the TMI was calculated. TMI values ranged from 0.09 to 3.87 (median: 0.50 ); $50.3 \%$ of patients had an elevated TMI value of $>0.5$. Among patients who had normal serum CEA and CYFRA 21-1 levels, 84 had an elevated TMI value. The CEA, CYFRA 21-1, and TMI data are summarized in Table 1.

Survival and univariate and multivariate analyses: The mean postoperative follow-up period was 2,004 days (65.9 months), ranging from 46 to 2,995 days (1.5-97.2 months). The 5-year survival rate was $85.0 \%$.

The 5-year OS and DFS rates were significantly lower for patients with elevated serum CEA levels than for patients with normal CEA levels $(\mathrm{P}<0.01$ and $\mathrm{P}<0.001$, respectively) (Figure $2 \mathrm{~A}$ and Table 2). Similarly, OS and DFS rates were significantly lower for patients with elevated serum CYFRA 21-1 levels than for patients with normal CYFRA 21-1 levels $(\mathrm{P}<0.01$ and $\mathrm{P}<0.05$, respectively) (Figure $2 \mathrm{~B}$ and Table 2). In addition, significantly lower OS and DFS rates were observed for patients with an elevated TMI value than for patients with a normal TMI value $(\mathrm{P}<0.001$ for both $\mathrm{OS}$ and DFS) (Figure $2 \mathrm{C}$ and Table 2)
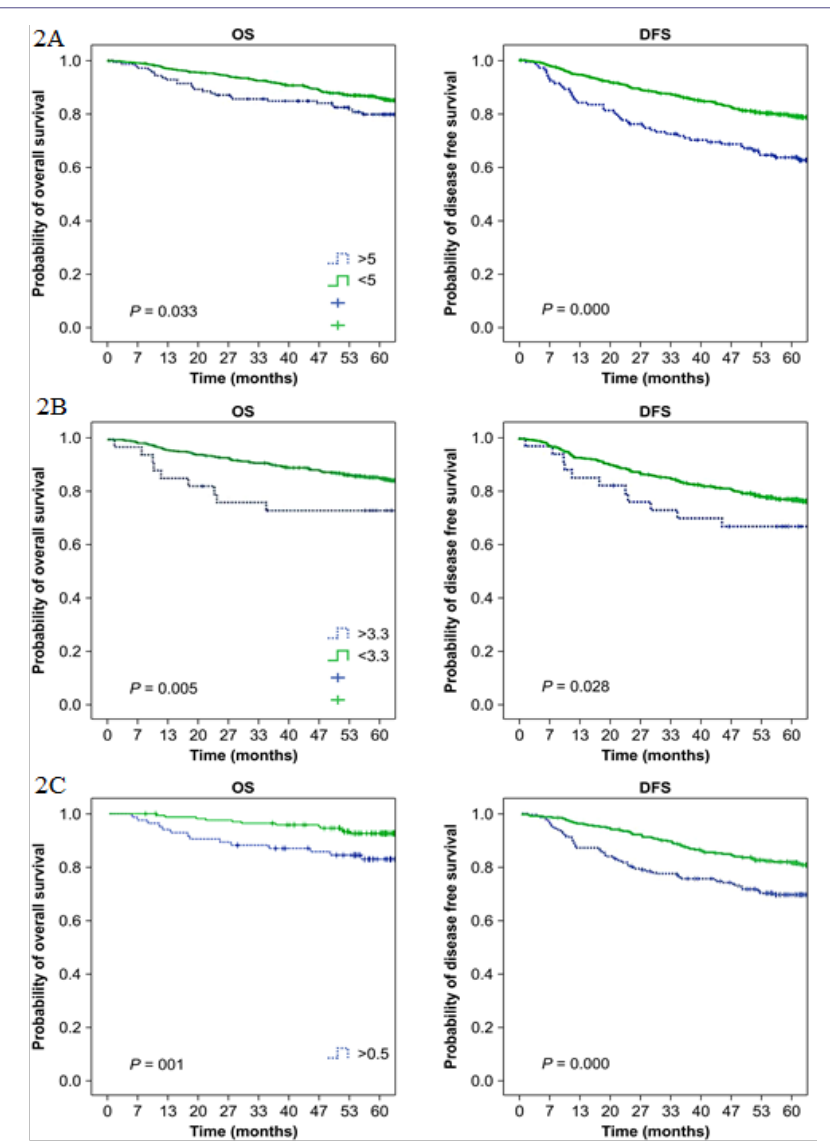

Figure 2: Kaplan-Meier Curves for (OS; Left) and (DFS; Right) According to (A) carcinoembryonic antigen, (B) Cytokeratin-19 fragment, and (C) tumor marker index values. Green curves represent normal values and blue curves represent elevated values of the markers.

The clinical variables associated with a significantly poorer survival that were identified by univariate analysis included: male sex (mean survival: 1,785 days in men vs. 1,940 days in women; $\mathrm{P}<0.01$ ), smoking history $(1,771$ days in smokers vs. 1,972 days in non-smokers; $\mathrm{P}<0.01)$, tumor size $(1,651$ days for tumors $>3.0 \mathrm{~cm}$ vs. 1,978 days for tumors $<3.0 \mathrm{~cm} ; \mathrm{P}<0.001)$, and tumor histology $(1,353$ days for non-adenocarcinoma vs. 1,794 days for adenocarcinoma; $\mathrm{P}<0.0001$ ) (Table 3 and Table 4).

Univariate analysis of preoperative tumor markers confirmed their significance for OS (Table 3). The mean survival of patients with serum CEA levels of $>5.0 \mathrm{ng} / \mathrm{mL}$ was 1,454 days compared to 1,869 days for patients with serum CEA levels of $<5.0 \mathrm{ng} / \mathrm{mL}(\mathrm{P}<0.05)$. The mean survival of patients with serum CYFRA 21-1 levels of $>3.3 \mathrm{ng} /$ $\mathrm{mL}$ was 1,472 days compared to 1,845 days for patients with serum CYFRA 21-1 levels of $<3.3 \mathrm{ng} / \mathrm{mL}(\mathrm{P}<0.01)$. Patients in whom the calculated TMI value was $>0.5$ had a lower mean survival than patients with a TMI value of $<0.5$ (1,702 vs. 1,944 days, respectively; $\mathrm{P}<0.01)$.

Multivariate analysis identified the TMI as being an independent prognostic factor not only for OS (hazard ratio: 1.966, 95.0\% confidence interval: $1.031-3.752$; $\mathrm{P}<0.05$ ), but also for DFS (hazard ratio: 1.563, 95.0\% confidence interval: 1.125-2.172; $\mathrm{P}<0.01$ ) (Table 4). According to the multivariate analysis, tumor size was an independent prognostic factor for DFS only and not OS. 
Citation: Yamaguchi G, Haghiwara M, Ikeda N (2019) Prognostic Value of the Tumor Marker Index Based on Preoperative Serum Carcinoembryonic Antigen and Cytokeratin-19 Fragment Levels for Overall and Disease-Free Survival in Patients with Stage I Non-Small Cell Lung Cancer. J Pulm Med Respir Res 5: 027.

\begin{tabular}{|c|c|c|c|c|c|c|c|c|c|}
\hline \multirow{3}{*}{ Survival } & \multicolumn{3}{|c|}{ CEA } & \multicolumn{3}{|c|}{ CYFRA 21-1 } & \multicolumn{3}{|c|}{ TMI } \\
\hline & Normal & Elevated & \multirow{2}{*}{$\mathbf{P}$} & Normal & Elevated & \multirow{2}{*}{$\mathbf{P}$} & Normal & Elevated & \multirow{2}{*}{$\mathbf{P}$} \\
\hline & $<5.0 \mathrm{ng} / \mathrm{mL}$ & $>5.0 \mathrm{ng} / \mathrm{mL}$ & & $<3.3 \mathrm{ng} / \mathrm{mL}$ & $>3.3 \mathrm{ng} / \mathrm{mL}$ & & $<0.5$ & $>0.5$ & \\
\hline OS Rate (\%) & 89.7 & 85.8 & $.005^{*}$ & 88.5 & 73.2 & $.005^{*}$ & 92.7 & 82.8 & $.001 *$ \\
\hline DFS Rate (\%) & 80.8 & 65.7 & $.001^{*}$ & 78.9 & 64.1 & $.028^{*}$ & 85.6 & 70.5 & $.001 *$ \\
\hline \multicolumn{10}{|l|}{$* \mathrm{P}<.05$} \\
\hline \multicolumn{10}{|c|}{ Abbreviations: DFS = disease-free survival; OS = overall survival. } \\
\hline
\end{tabular}

Table 2: Survival rates for patients with normal and elevated preoperative serum levels of Carcinoembryonic Antigen (CEA), Cytokeratin-19 Fragment (CYFRA 21-1), and the Tumor Marker Index (TMI).

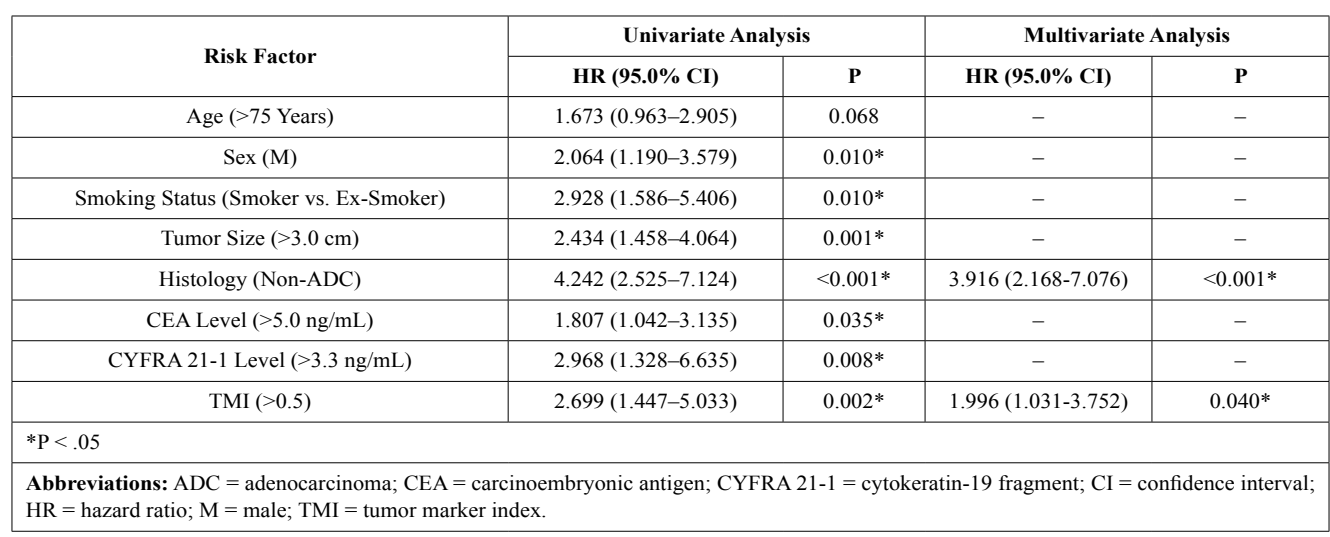

Table 3: Univariate and multivariate analyses of overall survival.

\begin{tabular}{|c|c|c|c|c|}
\hline \multirow{2}{*}{ Risk Factor } & \multicolumn{2}{|c|}{ Univariate Analysis } & \multicolumn{2}{|c|}{ Multivariate Analysis } \\
\hline & HR $(95.0 \% \mathrm{CI})$ & $\mathbf{P}$ & HR $(95.0 \% \mathrm{CI})$ & $\mathbf{P}$ \\
\hline Age (>75 Years) & $1.483(0.965-2.277)$ & 0.072 & - & - \\
\hline $\operatorname{Sex}(M)$ & $1.705(1.135-2.561)$ & $0.010^{*}$ & - & - \\
\hline Smoking Status (Smoker vs. Ex-Smoker) & $1.863(1.454-2.385)$ & $<0.010^{*}$ & - & - \\
\hline Tumor Size $(>3.0 \mathrm{~cm})$ & $2.190(1.731-2.771)$ & $<0.001^{*}$ & $1.568(1.130-2.176)$ & $0.007 *$ \\
\hline Histology (Non-ADC) & $2.071(1.747-2.455)$ & $<.001 *$ & $1.882(1.466-2.416)$ & $<0.001 *$ \\
\hline CEA Level $(>5.0 \mathrm{ng} / \mathrm{mL})$ & $1.948(1.471-2.579)$ & $<0.001 *$ & - & - \\
\hline CYFRA 21-1 Level (>3.3 ng/mL) & $1.897(1.152-3.066)$ & $0.012 *$ & - & - \\
\hline TMI $(>0.5)$ & $1.989(1.461-2.709)$ & $<0.001^{*}$ & $1.563(1.125-2.172)$ & $0.008^{*}$ \\
\hline \multicolumn{5}{|l|}{$* \mathrm{P}<.05$} \\
\hline $\begin{array}{l}\text { Abbreviations: } \mathrm{ADC}=\text { adenocarcinoma } \mathrm{CEA} \\
\mathrm{HR}=\text { hazard ratio } ; \mathrm{M}=\text { male } ; \mathrm{TMI}=\text { tumor mar }\end{array}$ & nbryonic antigen; $\mathrm{CY}$ & $1-1=$ cyto & in-19 fragment; $\mathrm{CI}=$ & nce inte \\
\hline
\end{tabular}

Table 4: Univariate and multivariate analyses of disease-free survival.

When survival analysis was performed on patients $(n=84)$ who had normal preoperative serum CEA and CYFRA 21-1 levels, but an elevated TMI value, significant differences in the OS and DFS rates were found compared to patients who had all three parameters that were normal (Figure 3A). The 5-year OS rate was $82.8 \%$ in patients with a TMI value of $>0.5$ and $92.6 \%$ in patients with a TMI value of $<0.5(\mathrm{P}<0.05)$. The 5 -year DFS rate was $70.9 \%$ in patients with a TMI value of $>0.5$ and $86.0 \%$ in patients with a TMI value of $<0.5$ $(\mathrm{P}<0.01)$ (Figure 3B).

The DFS and OS are significantly different from the patient who had normal preoperative serum CEA and CYFRA211 levels but an elevated TMI (mean DFS and OS are 16111 days and 1737days), the patients with low three indicators and the patient with elevated CEA or CYFRA211 and TMI (mean DFS and OS are 1383 days and 1461 days).

\section{Discussion}

Surgery provides the best option for long-term survival in Stage III NSCLC [44]. In addition, adjuvant platinum-based chemotherapy has been shown to be beneficial, especially for patients with Stage II NSCLC [45]. A high incidence of disease recurrence in Stage I patients after complete resection suggests that these patients also might be candidates for adjuvant chemotherapy. 
Citation: Yamaguchi G, Haghiwara M, Ikeda N (2019) Prognostic Value of the Tumor Marker Index Based on Preoperative Serum Carcinoembryonic Antigen and Cytokeratin-19 Fragment Levels for Overall and Disease-Free Survival in Patients with Stage I Non-Small Cell Lung Cancer. J Pulm Med Respir Res 5: 027.

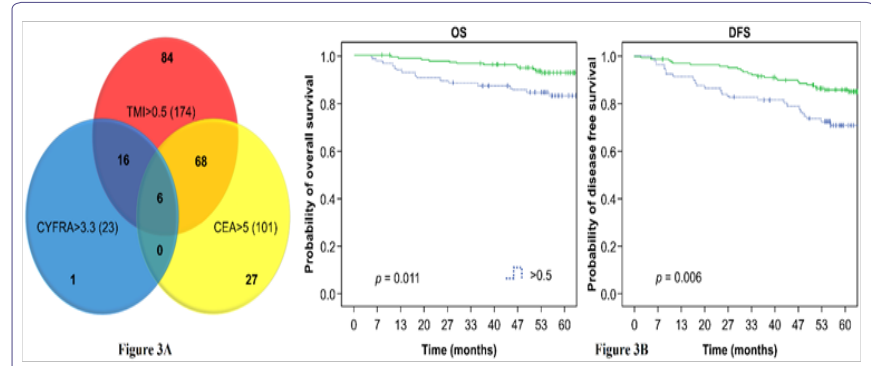

Figure 3: (A) Patients (84) with (CEA) and (CYFRA 21-1) and elevated Tumor Marker Index (TMI). (B) Overall Survival (OS; Left) and Disease-Free Survival (DFS; Right) for the above 84 patients. Green curves represent normal values and blue curves represent elevated values.

Although there are many demographic, clinical, genetic, and pathological parameters that should be taken into consideration during decision making for postoperative chemotherapy, a simple preoperative prognostic test that could overcome the heterogeneous clinical and morphological presentations of NSCLC should be developed. Herein, we present evidence that the TMI, a calculated parameter based on preoperative serum CEA and CYFRA 21-1 levels, is a valid and independent prognostic indicator not only for postoperative OS, but also for DFS.

In accordance with several previous reports $[5,6]$ our results demonstrate that male sex, smoking history, tumor size and histology are independent prognostic factors in NSCLC. We validated the significance of the TMI for the prediction of OS in a much larger cohort than those of previous studies [40-43]. The number of patients included in the study was 454 compared to 153,261 , and 293 patients in previous studies. Furthermore, our patient population consisted of an almost equal number of men and women (252 vs. 202). This is important given the sex differences in survival in patients with NSCLC [46].

All patients included in this study underwent lobe-specific selective lymph node dissection (known as ND2a-1 in Japan), which results in high OS [47]. In our study5-year survival rates were approximately $80.0 \%$. Moreover, the proportion of patients with large cell carcinoma, who usually have a poor prognosis, was relatively low in our study $(<20.0 \%)$. Despite high survival rates, we were able to demonstrate the effectiveness of the TMI in predicting a poor prognosis. In a previous study, Blankenburg et al. reported that the survival rates in $40.0 \%$ of patients with large cell carcinoma were $<55.0 \%$. The low OS rates may explain their inability to demonstrate the prognostic significance of the TMI [43].

To further investigate the prognostic value of the TMI, we plotted Kaplan-Meier curves of DFS according to the TMI (Figure 2C and Table 2) and performed univariate and multivariate analyses (Table 4). Our data demonstrated that the TMI is an independent prognostic indicator not only for OS but also for DFS, suggesting that it could be utilized for the prediction of potential disease recurrence, and thus could contribute to the decision making for postoperative chemotherapy.

Our study for the first time demonstrates advantage of TMI compared serum CEA and CYFRA 21-1 levels separately. We show that individual CEA and CYFRA 21-1 measurements often produce non-overlapping results in the same patient population. For example, among 101 patients with elevated serum CEA levels and 23 patients with elevated CYFRA 21-1 levels, the levels of both markers were simultaneously elevated in only 6 patients. Similarly, among 325 patients with normal CYFRA 21-1 levels, 95 patients had elevated serum CEA levels. Furthermore, we found that among 174 patients with an elevated TMI value, 84 had normal CEA and CYFRA 21-1 levels (Figure 3A).

We standardized the prognostic threshold of the TMI as 0.5 using ROC analysis. Previous studies [40-43], used a critical level approach that resulted in various TMI cutoff values for the prediction of survival, complicating the comparison of results between different reports. For instance, Blankenburg et al. defined several prognostic cutoff values for the TMI based on survival curves [43]. They also used a different diagnostic threshold for CEA assay, which may explain the discrepancy between their results and our own.

In accordance with our findings, the TMI has been shown to correlate with imaging characteristics of high-resolution computed tomography, predicting a poor prognosis in early-stage lung adenocarcinoma [47]. Elevated TMI also correlated with a poor survival in aggressive adenosquamous lung carcinoma with a relatively high frequency of EGFR mutations [48].

The TMI has also been calculated for different tumor markers, e.g. for preoperative CEA and Krebs von den Lungen-6 levels in NSCLC [49]. In general, the utilization of a combination of several markers appears to be a more advantageous approach for the diagnosis and assessment of chemotherapy response in lung cancer and other cancer types [50]. For example, a comparison of the diagnostic sensitivity of various combinations of serum tumor markers, including CEA and CYFRA 21-1, in patients with esophageal squamous cell carcinoma suggested that combinations of markers that included Chitinase-3like-1 protein and squamous cell carcinoma antigen had better diagnostic capabilities than CEA and CYFRA 21-1 for this type of cancer [51]. The usefulness of a prognostic marker index that is calculated as a combination of preoperative serum CEA and plasma tissue inhibitor of metalloproteinases- 1 levels for the assessment of the risk of disease recurrence has been demonstrated in patients with early-stage colorectal cancer [52].

Several limitations of our study should be considered. First, false-positive results associated with elevated CEA levels due to smoking could not be excluded [53]. Moreover, this retrospective study did not include the findings of a preoperative clinical examination of the patients, which could influence serum CEA levels. Second, variations in the rates of CEA and CYFRA 21-1 synthesis and elimination in highly heterogeneous lung tumors were not taken into consideration, and third, tumor depth and nodal status were not examined.

\section{Conclusion}

The TMI based on preoperative serum CEA and CYFRA 21-1 levels is an independent predictor of a poor prognosis in early-stage NSCLC. Strict follow-up and consideration for postoperative adjuvant chemotherapy is suggested for patients with elevated TMI values. Clinical trials testing the association between TMI values and disease recurrence, as well as, the effectiveness of adjuvant chemotherapy in patients with elevated TMI values should further confirm our findings. 
Citation: Yamaguchi G, Haghiwara M, Ikeda N (2019) Prognostic Value of the Tumor Marker Index Based on Preoperative Serum Carcinoembryonic Antigen and Cytokeratin-19 Fragment Levels for Overall and Disease-Free Survival in Patients with Stage I Non-Small Cell Lung Cancer. J Pulm Med Respir Res 5: 027.

\section{Disclosure Statement}

The authors have no conflicts of interest.

\section{Source(s) of Support}

This research did not receive any specific grant from funding agencies in the public, commercial, or not-for-profit sectors.

\section{Acknowledgements}

Editorial support, in the form of medical writing, assembling tables, and creating high-resolution images based on the authors' detailed instructions, collating author comments, copyediting, fact checking, and referencing, was provided by Cactus Communications.

\section{References}

1. Sagawa M, Nakayama T, Tanaka M, Sakuma T, JECS Study Group, et al. (2012) A randomized controlled trial on the efficacy of thoracic CT screening for lung cancer in non-smokers and smokers of $<30$ pack-years aged 50-64 years (JECS study): research design. Jpn J Clin Oncol 42: 12191221 .

2. Midthun DE (2016) Early detection of lung cancer. F1000Res 5: 739.

3. Saisho S, Yasuda K, Maeda A, Yukawa T, Okita R, et al. (2013) Post-recurrence survival of patients with non-small-cell lung cancer after curative resection with or without induction/adjuvant chemotherapy. Interact Cardiovasc Thorac Surg 16: 166-172.

4. Cho S, Song IH, Yang HC, Kim K, Jheon S (2013) Predictive factors for node metastasis in patients with clinical stage I non-small cell lung cancer. Ann Thorac Surg 96: 239-245.

5. Holdenrieder S, Pagliaro L, Morgenstern D, Farshid D (2016) Clinically meaningful use of blood tumor markers in oncology. Biomed Res Int 2016 : 9795269 .

6. Wallerek S, Sørensen JB (2015) Biomarkers for efficacy of adjuvant chemotherapy following complete resection in NSCLC stages I-IIIA. Eur Respir Rev 24: 340-355.

7. Grunnet M, Sorensen JB (2012) Carcinoembryonic antigen (CEA) as tumor marker in lung cancer. Lung Cancer 76: 138-143.

8. Matsuguma H, Nakahara R, Igarashi S, Ishikawa Y, Suzuki H, et al. (2008) Pathologic stage I non-small cell lung cancer with high levels of preoperative serum carcinoembryonic antigen: clinicopathologic characteristics and prognosis. J Thorac Cardiovasc Surg 135: 44-49.

9. Kawachi R, Nakazato Y, Takei H, Koshi-ishi Y, Goya T (2009) Clinical significance of preoperative carcinoembryonic antigen level for clinical stage I non-small cell lung cancer: can preoperative carcinoembryonic antigen level predict pathological stage? Interact Cardiovasc Thorac Surg 9: 199-202.

10. Ozeki N, Fukui T, Taniguchi T, Usami N, Kawaguchi K, et al. (2014) Significance of the serum carcinoembryonic antigen level during the follow-up of patients with completely resected non-small-cell lung cancer. Eur J Cardiothorac Surg 45: 687-692.

11. Wang XB, Li J, Han Y (2014) Prognostic significance of preoperative serum carcinoembryonic antigen in non-small cell lung cancer: a meta-analysis. Tumour Biol 35: 10105-10110.

12. Tomita M, Matsuzaki Y, Edagawa M, Shimizu T, Hara M, et al. (2004) Prognostic significance of preoperative serum carcinoembryonic antigen level in lung adenocarcinoma but not squamous cell carcinoma. Ann Thorac Cardiovasc Surg 10: 76-80.
13. Kato T, Ishikawa K, Aragaki M, Sato M, Okamoto K, et al. (2013) Optimal predictive value of preoperative serum carcinoembryonic antigen for surgical outcomes in stage I non-small cell lung cancer: differences according to histology and smoking status. J Surg Oncol 107: 619-624.

14. Gaspar MJ, Diez M, Rodriguez A, Ratia T, Martin Duce A, et al. (2003) Clinical value of CEA and CA125 regarding relapse and metastasis in resectable non-small cell lung cancer. Anticancer Res 23: 3427-3432.

15. Liu H, Gu X, Lv T, Wu Y, Xiao Y, et al. (2014) The role of serum carcinoembryonic antigen in predicting responses to chemotherapy and survival in patients with non-small cell lung cancer. J Cancer Res Ther 10: 239-243.

16. Maeda R, Suda T, Hachimaru A, Tochii D, Tochii S, et al. (2017) Clinical significance of preoperative carcinoembryonic antigen level in patients with clinical stage IA non-small cell lung cancer. J Thorac Dis 9: 176-186.

17. Kosacka M, Jankowska R (2009) Comparison of cytokeratin 19 expression in tumor tissue and serum CYFRA 21-1 levels in non-small cell lung cancer. Pol Arch Med Wewn 119: 33-37.

18. Wieskopf B, Demangeat C, Purohit A, Stenger R, Gries P, et al. (1995) Cyfra 21-1 as a biologic marker of non-small cell lung cancer. Evaluation of sensitivity, specificity, and prognostic role. Chest 108: 163-169.

19. Pujol JL, Grenier J, Daurès JP, Daver A, Pujol H, et al. (1993) Serum fragment of cytokeratin subunit 19 measured by CYFRA 21-1 immunoradiometric assay as a marker of lung cancer. Cancer Res 53: 61-66.

20. Kao CH, Hsieh JF, Ho YJ, Tsai SC, Lee JK (1999)Cytokeratin fragment 19 (CYFRA 21-1) in healthy smokers. Anticancer Res19: 4545-4546.

21. Takahashi H, Kurishima K, Ishikawa H, Kagohashi K, Kawaguchi M, et al. (2010) Optimal cutoff points of CYFRA21-1 for survival prediction in non-small cell lung cancer patients based on running statistical analysis. Anticancer Res 30: 3833-3837.

22. Zhao H, Shi X, Liu J, Chen Z, Wang G (2014) Serum cyfra21-1 as a biomarker in patients with non-small cell lung cancer. J Cancer Res Ther 10: 215-217.

23. Xu Y, Xu L, Qiu M, Wang J, Zhou Q, et al. (2015) Prognostic value of serum cytokeratin 19 fragments (Cyfra 21-1) in patients with non-small cell lung cancer. Sci Rep 5: 9444.

24. Yu Z, Zhang G, Yang M, Zhang S, Zhao B, et al. (2017) Systematic review of CYFRA 21-1 as a prognostic indicator and its predictive correlation with clinicopathological features in Non-small Cell Lung Cancer: A meta-analysis. Oncotarget 8: 4043-4050.

25. Hanagiri T, Sugaya M, Takenaka M, Reinmiedl J, Gruber C, et al. (2011) Preoperative CYFRA $21-1$ and CEA as prognostic factors in patients with stage I non-small cell lung cancer. Lung Cancer 74: 112-117.

26. Zhang L, Liu D, Li L, Pu D, Zhou P, et al. (2017) The important role of circulating CYFRA21-1 in metastasis diagnosis and prognostic value compared with carcinoembryonic antigen and neuron-specific enolase in lung cancer patients. BMC Cancer 17: 96

27. Duan X, Cui Y, Li H, Shi G, Wu B, et al. (2015) High preoperative and postoperative levels of carcinoembryonic antigen and CYFRA 21-1 indicate poor prognosis in patients with pathological Stage I nonsmall cell lung cancer. Indian J Cancer 52: 158-163.

28. Zhang ZH, Han YW, Liang H, Wang LM (2015) Prognostic value of serum CYFRA21-1 and CEA for non-small-cell lung cancer. Cancer Med 4: $1633-1638$.

29. Matsuoka K, Sumitomo S, Nakashima N, Nakajima D, Misaki N (2007) Prognostic value of carcinoembryonic antigen and CYFRA21-1 in patients with pathological stage I non-small cell lung cancer. Eur J Cardiothorac Surg 32: 435-439. 
Citation: Yamaguchi G, Haghiwara M, Ikeda N (2019) Prognostic Value of the Tumor Marker Index Based on Preoperative Serum Carcinoembryonic Antigen and Cytokeratin-19 Fragment Levels for Overall and Disease-Free Survival in Patients with Stage I Non-Small Cell Lung Cancer. J Pulm Med Respir Res 5: 027.

30. Szturmowicz M, Rudziński P, Kacprzak A, Langfort R, Bestry I, et al. (2014) Prognostic value of serum C-reactive protein (CRP) and cytokeratin 19 fragments (Cyfra 21-1) but not carcinoembryonic antigen (CEA) in surgically treated patients with non-small cell lung cancer. Pneumonol Alergol Pol 82: 422-429.

31. Cedrés S, Nuñez I, Longo M, Martinez P, Checa E, et al. (2011) Serum tumor markers CEA, CYFRA21-1, and CA-125 are associated with worse prognosis in advanced non-small-cell lung cancer (NSCLC). Clin Lung Cancer 12: 172-179.

32. Barlési F, Gimenez C, Torre JP, Doddoli C, Mancini J, et al. (2004) Prognostic value of combination of Cyfra 21-1, CEA and NSE in patients with advanced non-small cell lung cancer. Respir Med 98: 357-362.

33. Korbakis D, Dimitromanolakis A, Prassas I, Davis G J, Barber E, et al. (2015) Serum LAMC2 enhances the prognostic value of a multi-parametric panel in non-small cell lung cancer. Br J Cancer 113: 484-491.

34. Muley T, Dienemann H, Ebert W (2003) Increased CYFRA 21-1 and CEA levels are negative predictors of outcome in p-stage I NSCLC. Anticancer Res 23: 4085-4093.

35. Okamura K, Takayama K, Izumi M, Harada T, Furuyama K, et al. (2013) Diagnostic value of CEA and CYFRA 21-1 tumor markers in primary lung cancer. Lung Cancer 80: 45-49.

36. Ma L, Xie XW, Wang HY, Ma LY, Wen ZG (2015) Clinical evaluation of tumor markers for diagnosis in patients with non-small cell lung cancer in China. Asian Pac J Cancer Prev 16: 4891-4894.

37. McKeegan EM, Ansell PJ, Davis G, Chan S, Chandran RK, et al. (2015) Plasma biomarker signature associated with improved survival in advanced non-small cell lung cancer patients on linifanib. Lung Cancer 90: 296-301.

38. Muley T, Dienemann H, Ebert W (2008) CYFRA 21-1 and CEA are independent prognostic factors in 153 operated stage I NSCLC patients. Anticancer Res 24: 1953-1956.

39. Muley T, Fetz TH, Dienemann H, Hoffmann H, Herth FJ, et al. (2008) Tumor volume and tumor marker index based on CYFRA 21-1 and CEA are strong prognostic factors in operated early stage NSCLC. Lung Cancer 60: $408-415$

40. Tomita M, Shimizu T, Ayabe T, Yonei A, Onitsuka T (2010) Prognostic significance of tumour marker index based on preoperative CEA and CYFRA 21-1 in non-small cell lung cancer. Anticancer Res 30: 3099-3102.

41. Blankenburg F, Hatz R, Nagel D, Ankerst D, Reinmiedl J, et al. (2008) Preoperative CYFRA 21-1 and CEA as prognostic factors in patients with stage I non-small cell lung cancer: external validation of a prognostic score. Tumour Biol 29: 272-277.
42. Lemjabbar-Alaoui H, Hassan OU, Yang YW, Buchanan P (2015) Lung cancer: Biology and treatment options. Biochim Biophys Acta 1856: 189210

43. Sangha R, Price J, Butts CA (2010) Adjuvant therapy in non-small cell lung cancer: current and future directions. Oncologist 15: 862-872.

44. Sakurai H, Asamura H, Goya T, Eguchi K, Nakanishi Y, et al. (2010) Survival differences by gender for resected non-small cell lung cancer: a retrospective analysis of 12,509 cases in a Japanese Lung Cancer Registry study. J Thorac Oncol 5: 1594-1601.

45. Xu Y, Sun H, Zhang Z, Song A, Wang W, et al. (2016) Assessment of relationship between CT features and serum tumor marker index in early-stage lung adenocarcinoma. Acad Radiol 23: 1342-1348.

46. Zhi Q, Wang Y, Wang X, Yue D, Li K, et al. (2016) Predictive and prognostic value of preoperative serum tumor markers in resectable adenosqamous lung carcinoma. Oncotarget 7: 64798-64809.

47. Tomita M, Ayabe T, Chosa E, Nose N, Nakamura K (2017) Prognostic significance of a tumor marker index based on preoperative serum carcinoembryonic antigen and krebs von den lungen-6 levels in non-small cell lung cancer. Asian Pac J Cancer Prev 18: 287-291.

48. Ma R, Xu H, Wu J, Bai S, Dun B, et al. (2017) Identification of serum proteins and multivariate models for diagnosis and therapeutic monitoring of lung cancer. Oncotarget 8: 18901-18913.

49. Zheng X, Xing S, Liu XM, Liu W, Liu D, et al. (2014) Establishment of using serum YKL-40 and SCCA in combination for the diagnosis of patients with esophageal squamous cell carcinoma. BMC Cancer 14: 490.

50. Nielsen HJ, Christensen IJ, Brünner N (2010) A novel prognostic index in colorectal cancer defined by serum carcinoembryonic antigen and plasma tissue inhibitor of metalloproteinases-1. Scand J Gastroenterol 45: 200207.

51. Tomita M, Ayabe T, Chosa E, Nakamura K (2015) Impact of smoking on outcome of resected lung adenocarcinoma. Gen Thorac Cardiovasc Surg 63: 608-612.

52. Myerson RJ, Singh A, Birnbaum EH, Fry RD, Fleshman JW, et al. (2001) Pretreatment clinical findings predict outcome for patients receiving preoperative radiation for rectal cancer. Int J Radiat Oncol Biol Phys 50: 665674.

53. Li F, Shen Z, Lu Y, Wang L, Song W (2014) How much does body mass index affect serum carcinoembryonic antigen concentration? Cancer Epidemiol Biomarkers Prev 23: 555-560. 


\section{Hit}

Journal of Anesthesia \& Clinical Care

Journal of Addiction \& Addictive Disorders

Advances in Microbiology Research

Advances in Industrial Biotechnology

Journal of Agronomy \& Agricultural Science

Journal of AIDS Clinical Research \& STDs

Journal of Alcoholism, Drug Abuse \& Substance Dependence

Journal of Allergy Disorders \& Therapy

Journal of Alternative, Complementary \& Integrative Medicine

Journal of Alzheimer's \& Neurodegenerative Diseases

Journal of Angiology \& Vascular Surgery

Journal of Animal Research \& Veterinary Science

Archives of Zoological Studies

Archives of Urology

Journal of Atmospheric \& Earth-Sciences

Journal of Aquaculture \& Fisheries

Journal of Biotech Research \& Biochemistry

Journal of Brain \& Neuroscience Research

Journal of Cancer Biology \& Treatment

Journal of Cardiology: Study \& Research

Journal of Cell Biology \& Cell Metabolism

Journal of Clinical Dermatology \& Therapy

Journal of Clinical Immunology \& Immunotherapy

Journal of Clinical Studies \& Medical Case Reports

Journal of Community Medicine \& Public Health Care

Current Trends: Medical \& Biological Engineering

Journal of Cytology \& Tissue Biology

Journal of Dentistry: Oral Health \& Cosmesis

Journal of Diabetes \& Metabolic Disorders

Journal of Dairy Research \& Technology

Journal of Emergency Medicine Trauma \& Surgical Care

Journal of Environmental Science: Current Research

Journal of Food Science \& Nutrition

Journal of Forensic, Legal \& Investigative Sciences

Journal of Gastroenterology \& Hepatology Research

Journal of Gerontology \& Geriatric Medicine
Journal of Genetics \& Genomic Sciences

Journal of Hematology, Blood Transfusion \& Disorders

Journal of Human Endocrinology

Journal of Hospice \& Palliative Medical Care

Journal of Internal Medicine \& Primary Healthcare

Journal of Infectious \& Non Infectious Diseases

Journal of Light \& Laser: Current Trends

Journal of Modern Chemical Sciences

Journal of Medicine: Study \& Research

Journal of Nanotechnology: Nanomedicine \& Nanobiotechnology

Journal of Neonatology \& Clinical Pediatrics

Journal of Nephrology \& Renal Therapy

Journal of Non Invasive Vascular Investigation

Journal of Nuclear Medicine, Radiology \& Radiation Therapy

Journal of Obesity \& Weight Loss

Journal of Orthopedic Research \& Physiotherapy

Journal of Otolaryngology, Head \& Neck Surgery

Journal of Protein Research \& Bioinformatics

Journal of Pathology Clinical \& Medical Research

Journal of Pharmacology, Pharmaceutics \& Pharmacovigilance

Journal of Physical Medicine, Rehabilitation \& Disabilities

Journal of Plant Science: Current Research

Journal of Psychiatry, Depression \& Anxiety

Journal of Pulmonary Medicine \& Respiratory Research

Journal of Practical \& Professional Nursing

Journal of Reproductive Medicine, Gynaecology \& Obstetrics

Journal of Stem Cells Research, Development \& Therapy

Journal of Surgery: Current Trends \& Innovations

Journal of Toxicology: Current Research

Journal of Translational Science and Research

Trends in Anatomy \& Physiology

Journal of Vaccines Research \& Vaccination

Journal of Virology \& Antivirals

Archives of Surgery and Surgical Education

Sports Medicine and Injury Care Journal

International Journal of Case Reports and Therapeutic Studies 